\title{
A Challenging Surgical and Reconstructive Approach to Locally Advanced Squamous Perineal Carcinoma: A Case Report and Literature Review
}

\author{
Manuel Hevia Palacios ${ }^{1 *}$, Agustín Fraile Poblador ${ }^{1}$, Manuel Rodríguez Vegas ${ }^{2}$, Alberto Artiles Medina ${ }^{1}$, Arturo Vela \\ Lasagabaster $^{2}$, Rafael Rodríguez Patrón ${ }^{1}$, Moreno Moreno Esther ${ }^{3}$, Varona Crespo Constatino ${ }^{3}$, Ana Saiz González ${ }^{3}$, \\ Ana Ferrer Gómez ${ }^{3}$ and Javier Burgos Revilla ${ }^{1}$
}

${ }^{1}$ Urology Department, Ramón y Cajal Hospital, Madrid, Spain

${ }^{2}$ Plastic Surgery Department, Ramón y Cajal Hospital, Madrid, Spain

${ }^{3}$ Anatomic Pathology Department, Ramón y Cajal Hospital, Madrid, Spain

\section{A R TICLE INFO \\ Article history: \\ Received: 28 December, 2020 \\ Accepted: 14 January, 2021 \\ Published: 28 January, 2021 \\ Keywords: \\ Perineal carcinoma \\ reconstructive surgery \\ perineal surgery}

\begin{abstract}
A B S T R A C T
Perineal carcinoma of unknown primary origin (CUP) is a rare entity and represents a diagnostic and therapeutic challenge. These tumors may respond well to a combination of surgical resection, when feasible, local radiotherapy, and platinum-based systemic chemotherapy. A 67-year-old male patient consulted for urinary discomfort associated with perineal abscess. The perineal abscess was drained, and the patient was diagnosed with perineal carcinoma of unknown origin. Computed tomography (CT) scan shows a large perineal mass that involves both corpora cavernosa and corpus spongiosum. CT and bone scan excluded the metastatic spread of the disease. Inguinal lymph nodes were not identified. The surgical treatment consisted of two different phases. Phase I: the perineal mass exeresis with total penectomy. Phase II: perineal neourethrostomy with double oral mucosa graft. Coverage of the perineal defect and morphological reconstruction of the penis with fasciocutaneous and gracilis flap. The surgical intervention lasted for nine hours and the estimated blood loss was 500cc. The patient was discharged twelve days after the intervention. Later he received adjuvant treatment with immunotherapy (Cemiplimab) because was not subsidiary to treatment with platinum for renal failure. The patient died after nine months of follow-up due to pulmonary and abdominal metastatic spread.
\end{abstract}

Introduction

Carcinomas of unknown primary origin represent 3-5\% of all malignant tumors. Squamous cell CUP account for $5-10 \%$ of CUP, and the involvement of the male pelvis is extremely rare [1]. Perineal carcinoma can be derived, as in our case, from a process of inflammation and chronic infection in a patient with a urological history. Inflammatory process sustains the proliferation and survival of malignant transformed cells, can promote angiogenesis and metastatic processes, can negatively regulate the antitumoral adaptive and innate immune responses, and may alter the efficacy of therapeutic agents [2].

Initial presenting symptoms include buttock pain, rectal urgency, constipation, diarrhea, and urinary frequency [1]. Treatment regimens remain controversial, with limited cases to allow for consensus. Surgical intervention remains the leading form of therapy; however, approaches are case-specific, depending on the location of the tumor and the degree of invasiveness [3].

\section{Case Presentation}

A 67-year-old male patient with a medical history of diabetes mellitus, chronic renal failure and dyslipidemia consults for urinary discomfort associated with a perineal abscess. The physical examination reveals a fluctuating perineal tumor that spontaneously drains purulent content through the skin. The cystography shows a contrast extravasation at the level of the bulbar urethra compatible with the urethral fistula (Figure 1), and the endoscopic examination shows a devitalized bulbar urethra with a stenotic area that prevents the endoscope from passing. During the

${ }^{*}$ Correspondence to: Manuel Hevia Palacios, Urology Department, Ramón y Cajal Hospital, Ctra. Colmenar Viejo, km 9, 100, 28034, Madrid, Spain; E-mail: manuel.hevia.palacios@gmail.com,manuel.hevia@salud.madrid.es

(C) 2021 Manuel Hevia Palacios. This is an open-access article distributed under the terms of the Creative Commons Attribution License, which permits unrestricted use, distribution, and reproduction in any medium, provided the original author and source are credited. Hosting by Science Repository. http://dx.doi.org/10.31487/j.SCR.2021.01.15 
exploration, abundant saline solution was observed through the perineum. Surgical drainage of the collection was performed as well as the placement of a bladder and suprapubic catheter. The patient presented recurrence of the collection in the first month of follow-up, so it was decided to perform a new drainage of the abscess and a Friedrich of the perineal wound. The anatomopathological outcomes of the latter revealed the existence of a well-differentiated squamous cell carcinoma in areas of abundant keratinization that widely infiltrate the skin and soft tissue.

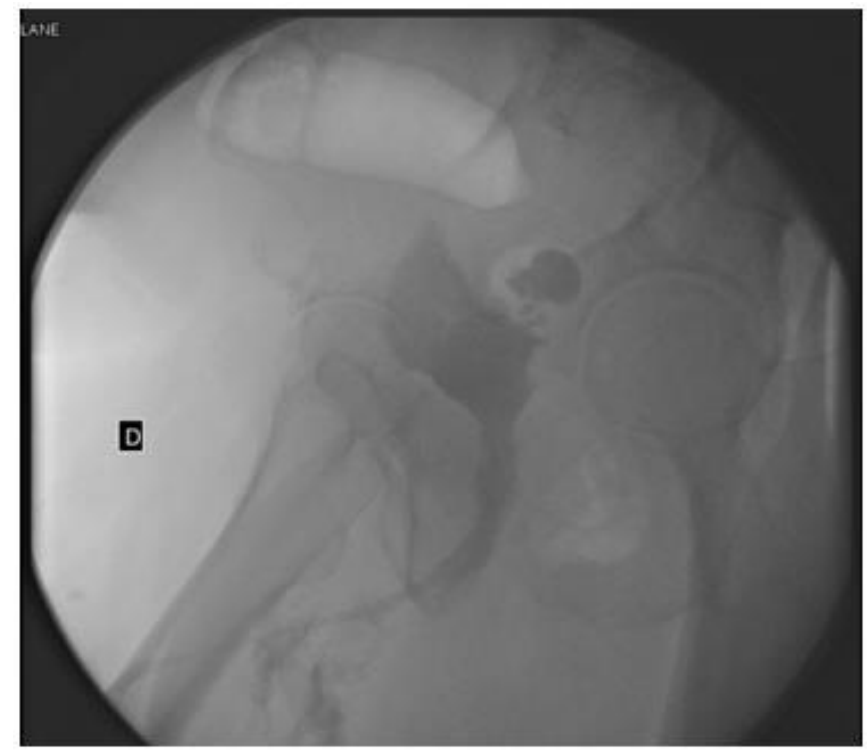

Figure 1: Cystography shows a small capacity bladder with irregular borders. Contrast extravasation is evident at the level of the middle bulbar urethra.

CT scan and MRI reveals a mass with irregular borders with a maximum diameter of $84 \mathrm{~mm}$ that invades both corpora cavernosa and the corpus

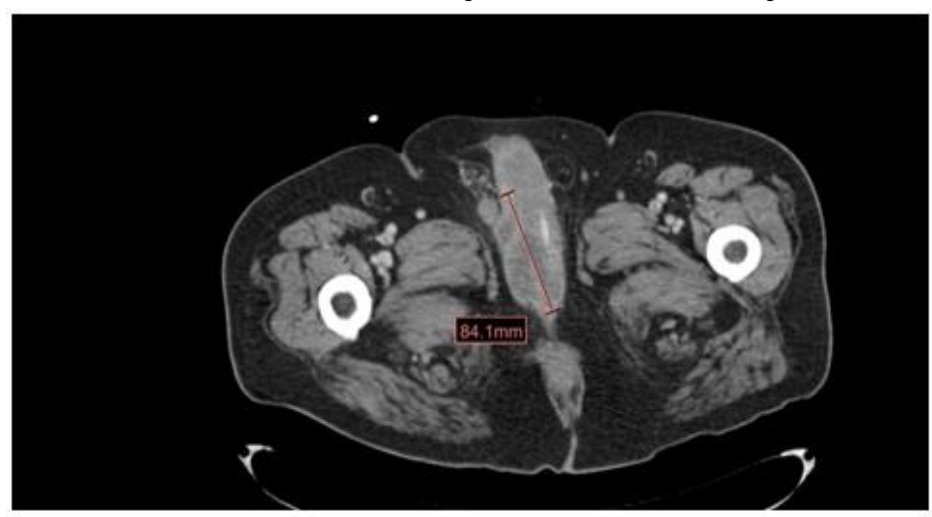

A spongiosum, reaching the urethral bulb (Figure 2). The extension study excluded the existence of the lymph node or visceral metastases.

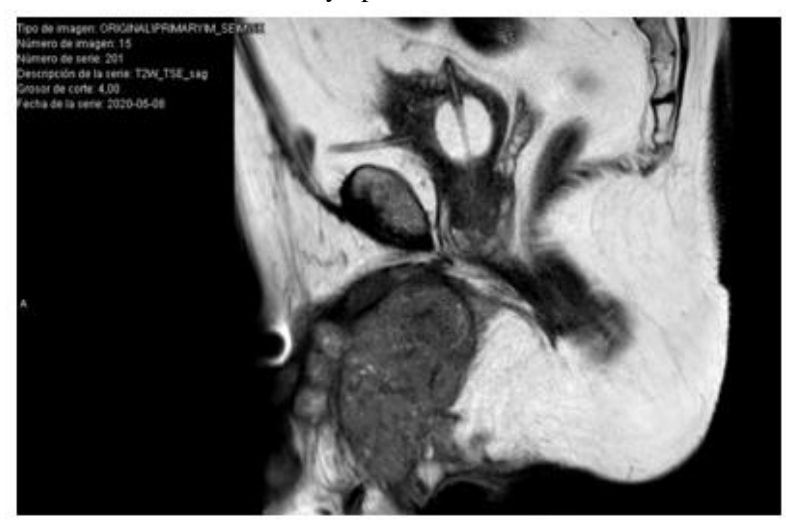

B

Figure 2: A) Irregular perineal mass affecting both corpora cavernosa; B) Sagittal magnetic resonance image in $\mathrm{T} 2$ phase showing a heterogeneous, polylobulated mass that extensively infiltrates both corpora cavernosa and perineal fat.

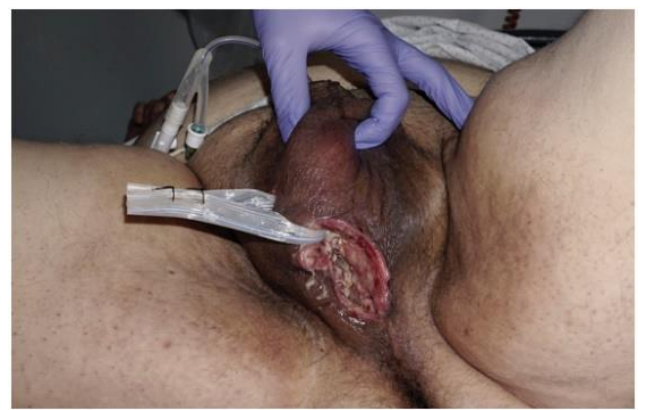

Figure 3: Perineal wound indurated on palpation with drainage of purulent material.
On physical examination, the patient presents a perineal wound with drainage of purulent material, indurated on palpation, and adhered to deep planes (Figure 3). The exeresis of the perineal mass with urethral reconstruction and subsequent coverage of the perineal defect with fasciocutaneous flaps was proposed to the patient.

\section{Surgical Procedure}

Low molecular weight heparin was administered 12 hours before the procedure. The intervention was carried out under general anaesthesia and with the collaboration of two surgical teams made up of urologists and plastic surgeons. 
On the part of plastic surgery, a planning is carried out for the extraction of the fasciocutaneous flaps to cover the perineal defect and of both gracilis for the morphological reconstruction of the penis and provide

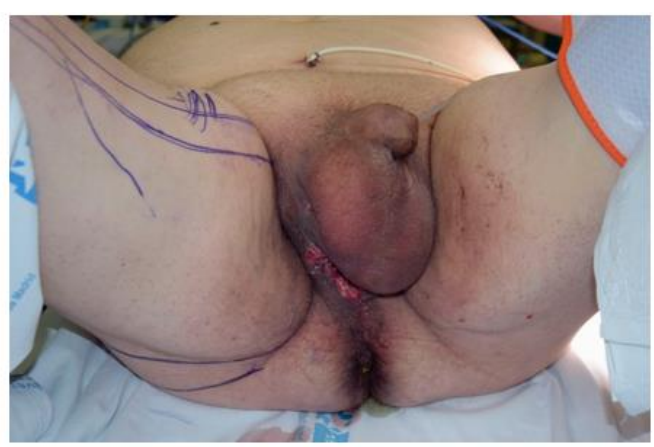

vascular support to the neourethra (Figure 4). The surgical procedure consisted of different phases -

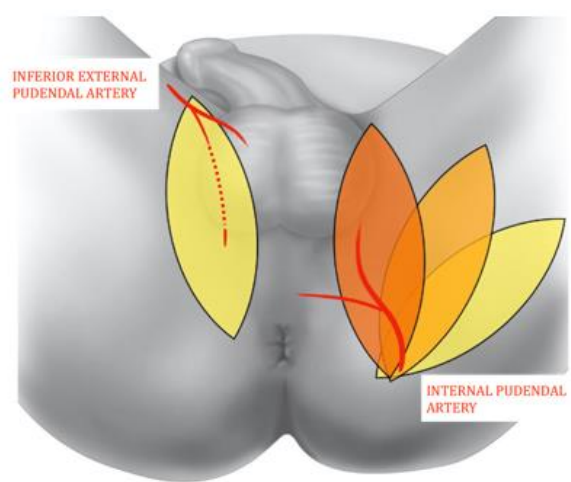

Courtesy of J.M. Rodríguez Vegas

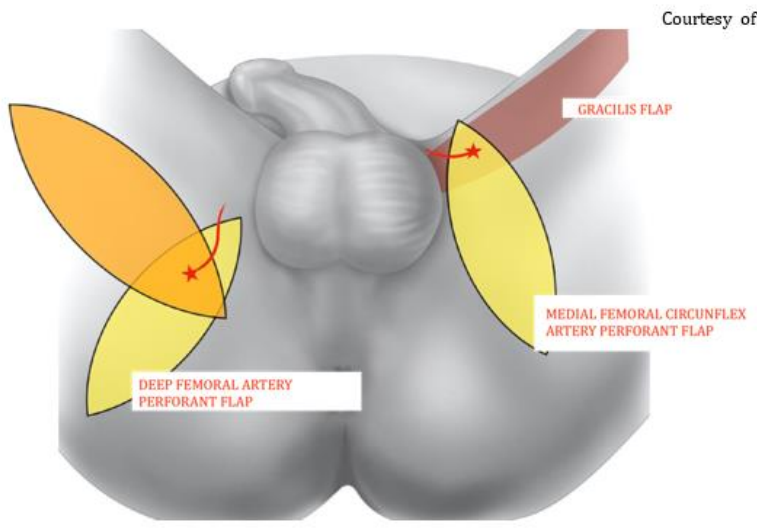

Courtesy of J.M. Rodríguez Vegas

Figure 4: Main fasciocutaneous flaps for the coverage of perineal defects.

Phase I: The patient is placed in a forced lithotomy position, and an incision is made with a cold scalpel on the limits of the mass in the cutaneous plane (Figure 5). The bulbar urethra and the corpora cavernosa are removed from their roots. Penile degloving is performed, and the penis is extracted through the perineal incision, thus achieving an en bloc removal of all tumor tissue (Figure 6).

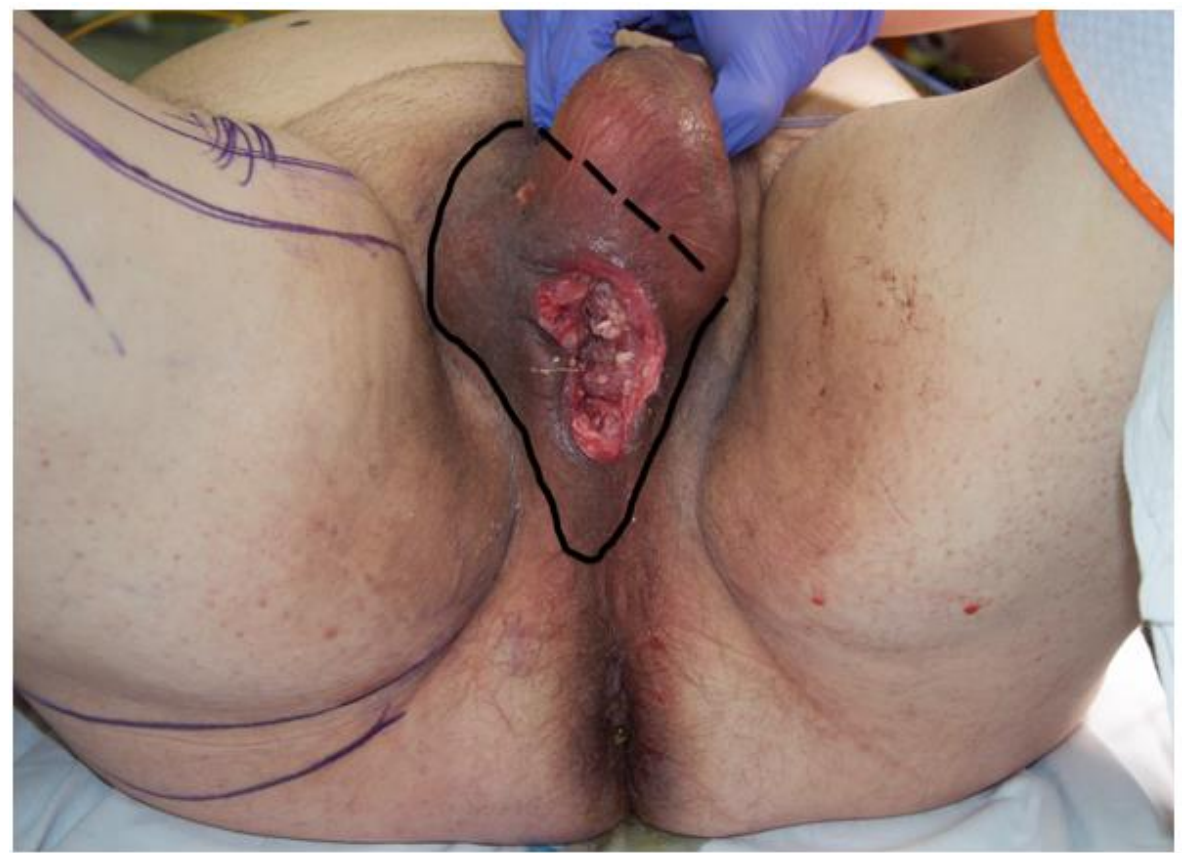

Figure 5: Cutaneous incision over the limits of the mass. 


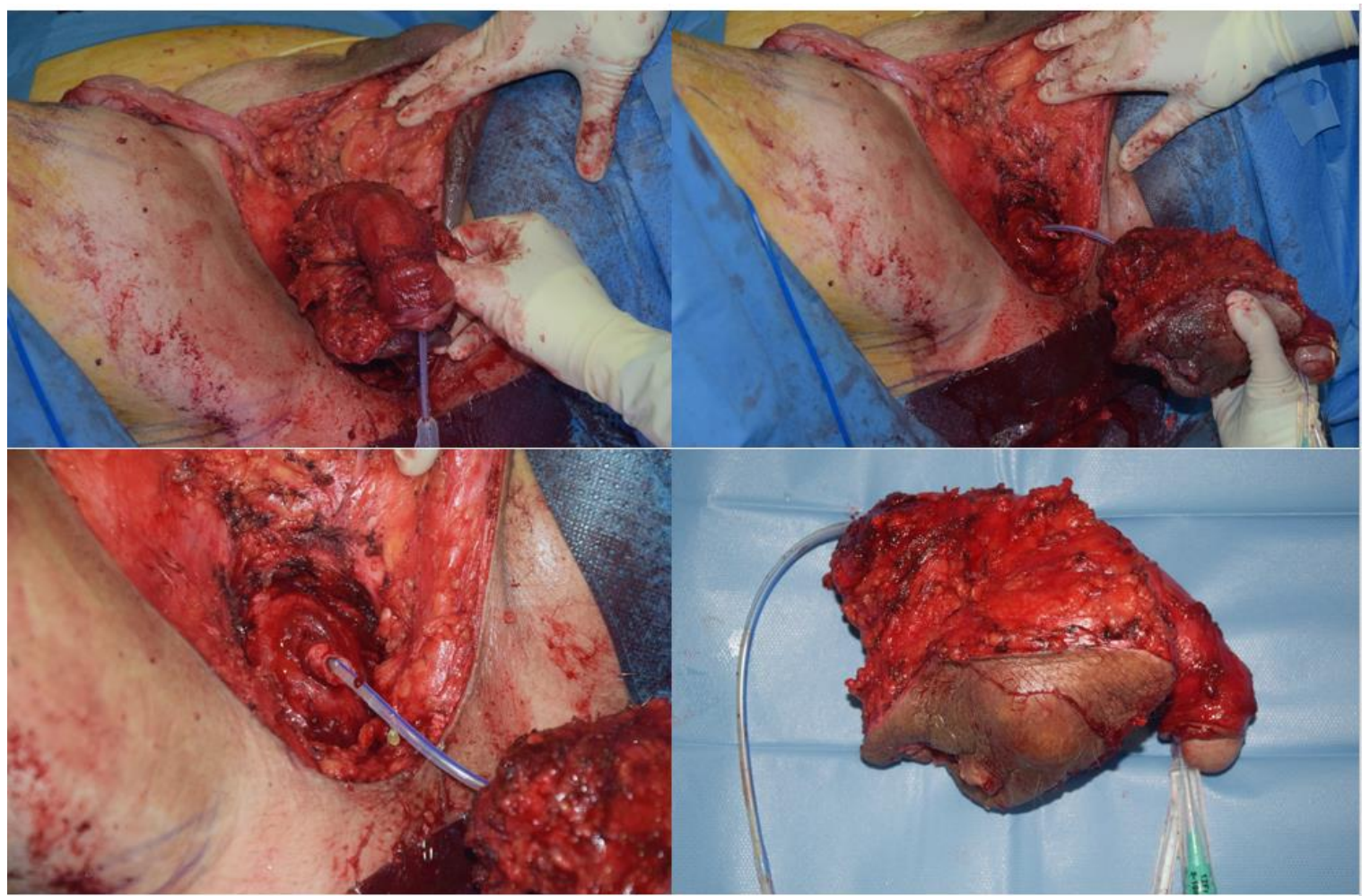

Figure 6: En bloc excision of tumor tissue with total penectomy. The remaining healthy urethra segment corresponding to the membranous urethra, and proximal to it, the prostatic apex, can be seen.

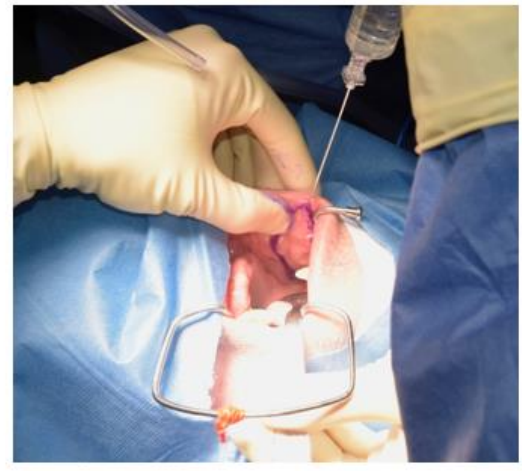

A

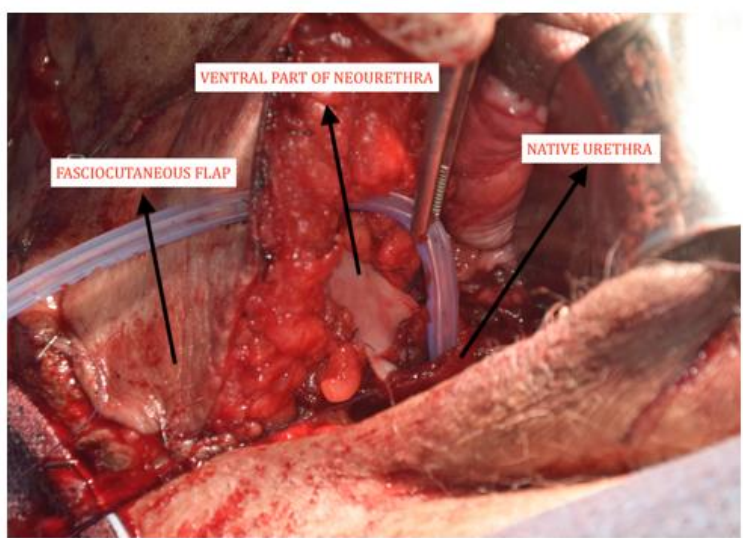

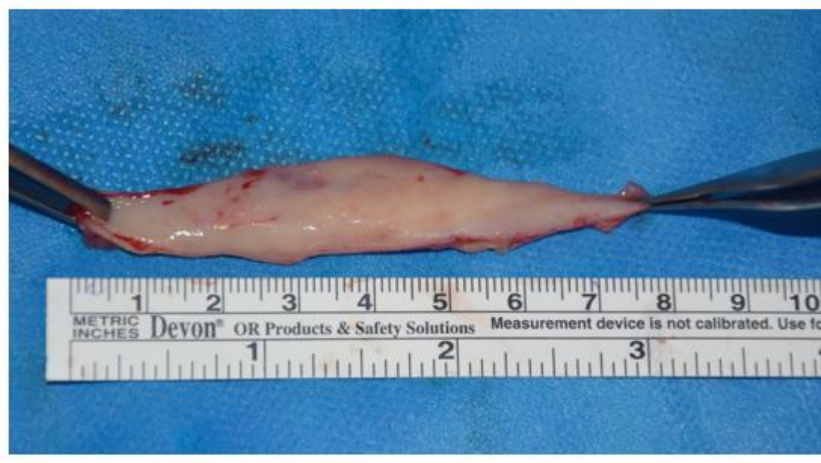

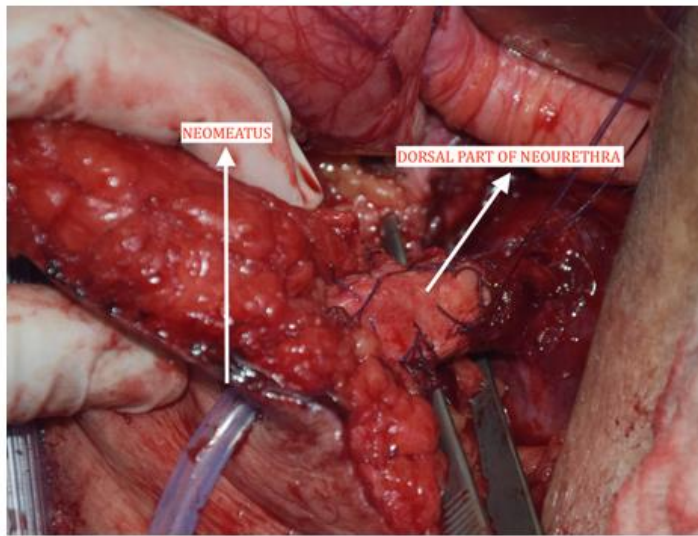

Figure 7: A \& B) $8 \mathrm{~cm}$ oral mucosa graft is removed and tubularized in two grafts forming the distal portion of the neourethra. C \& D) The neomeatus is removed through the fasciocutaneous flap. 
Phase II: First, an $8 \mathrm{~cm}$ oral mucosa graft is extracted, and the neourethra is performed with a double graft and the neomeatus is anastomosed to the skin of the flap (Figure 7).

The internal pudendal fasciocutaneous flap is performed according to the scheme proposed in (Figure 4). Subsequently, the gracilis flap (left) is

A

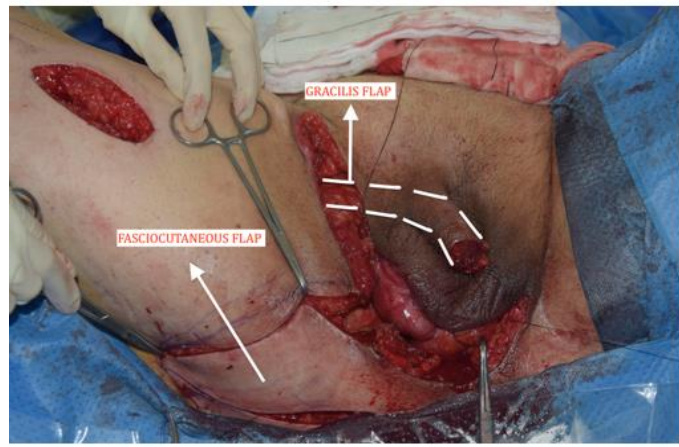

C

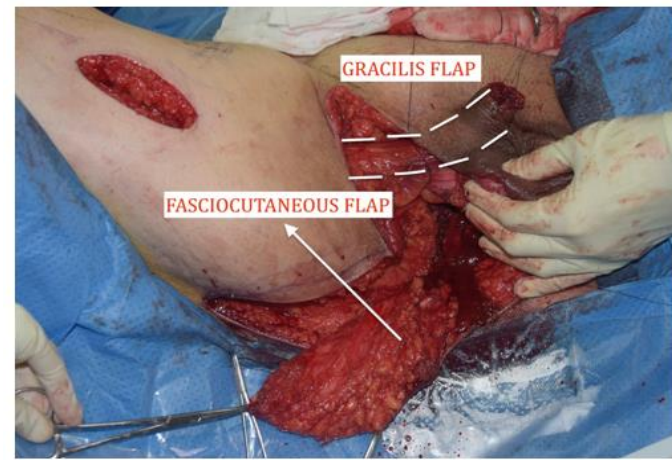

Figure 8: A) Internal pudendal fasciocutaneous flap is performed. B) Gracilis flap (left) is removed to provide vascular support to the neourethra, and C) the contralateral gracilis flap is dissected and inserted through the penile skin to give the neopenis an aesthetic and morphological appearance. D) Partial skin graft is performed to reconstruct the neoglans.

The procedure lasted 9 hours and the estimated blood loss was $500 \mathrm{cc}$. During the postoperative period, the patient remained with the urinary catheter through the neourethra, a suprapubic catheter and a rectal catheter to keep the receiving area of the flap as dry as possible. The patient was discharged on the twelfth day after surgery. During admission, he presented with a superficial dehiscence of the skin of the flap that was successfully treated with local paraffin dressings in addition to a partial retraction of the neoglans skin graft (Figure 9).

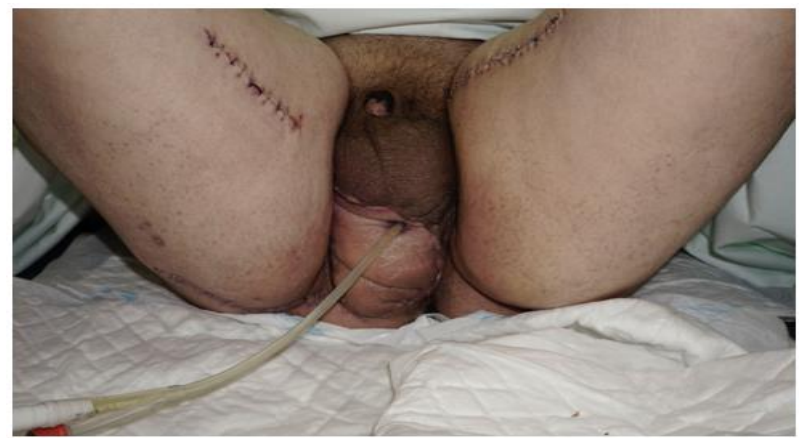

Figure 9: Superficial dehiscence of the skin and partial retraction of the neoglans.

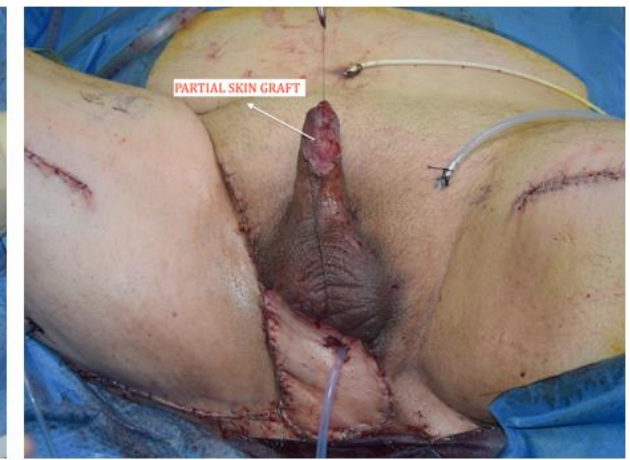

removed to cover the dead space and provide vascular support to the neourethra, and the contralateral gracilis flap is dissected and inserted through the penile skin to give the neopenis an aesthetic and morphological appearance. A partial skin graft is performed to reconstruct the neoglans (Figure 8). Four drains are placed, one in the surgical bed and the other three in the corresponding donor zones.

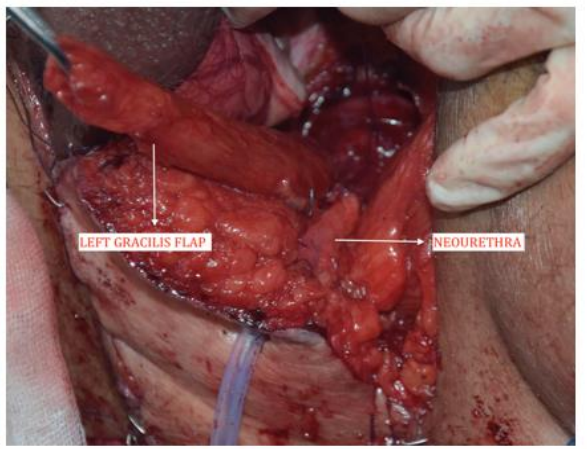

D

The surgical specimen corresponds to a $16.5 \times 11 \times 9 \mathrm{~cm}$ penectomy piece consisting of penis and perineum. It shows a $10.5 \mathrm{~cm}$ solid mass with whitish cut surface and infiltrative borders. This tumor is localized in perineum and it ulcerates the skin and reaches the base of the penis and cavernous bodies (Figure 10). Histological study reveals a moderately differentiated squamous cell carcinoma with keratinization and pleomorphic areas. The tumor shows neurotropism and frequent mitotic figures. The surgical edges were not compromised.

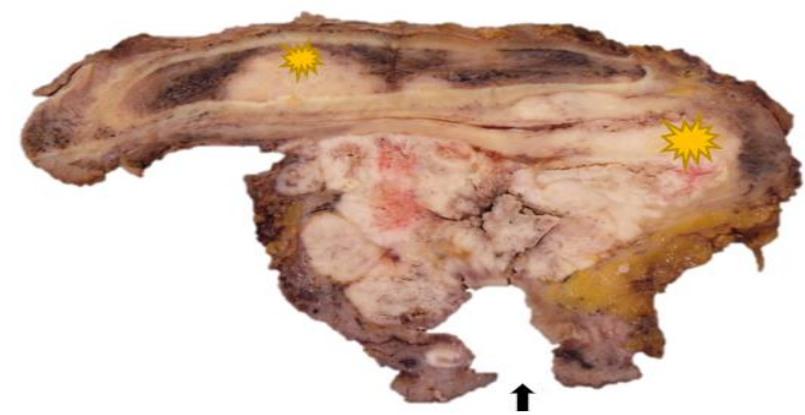

Figure 10: Macroscopic view of penectomy specimen. A large perineal ulcer is seen (arrow). The tumor reaches the base of the penis and cavernous bodies (asterisks). 
The patient presented a satisfactory postoperative period, being able to remove the urinary catheter and suprapubic catheter at 3 weeks (Figure 11), achieving spontaneous urination without involuntary leakage of urine due to the preservation of the internal urinary sphincter (bladder neck). After the removal of the bladder catheter, a cystography was performed showing a good urethral caliber without contrast leakage (Figure 12).

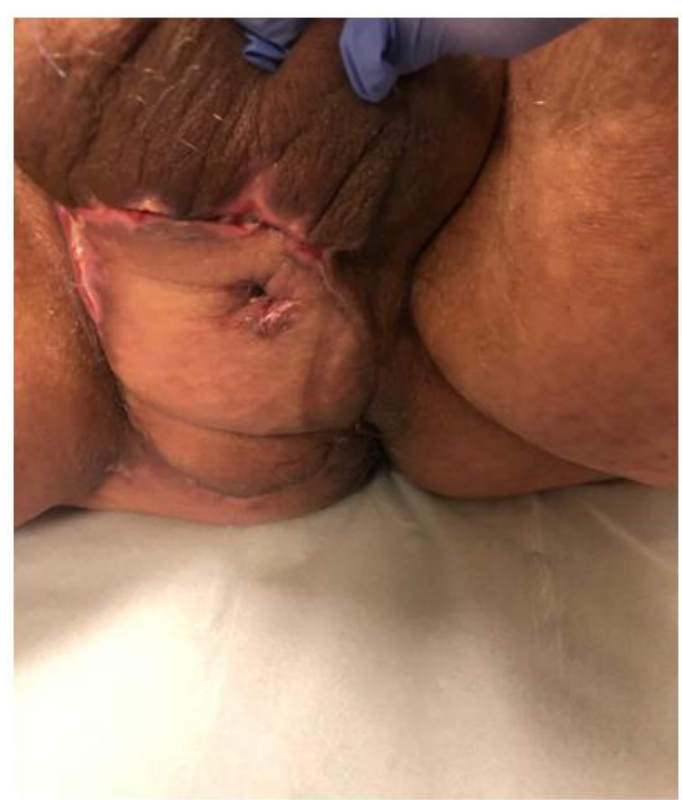

Figure 11: Third postoperative week after removal of the bladder and suprapubic catheter.

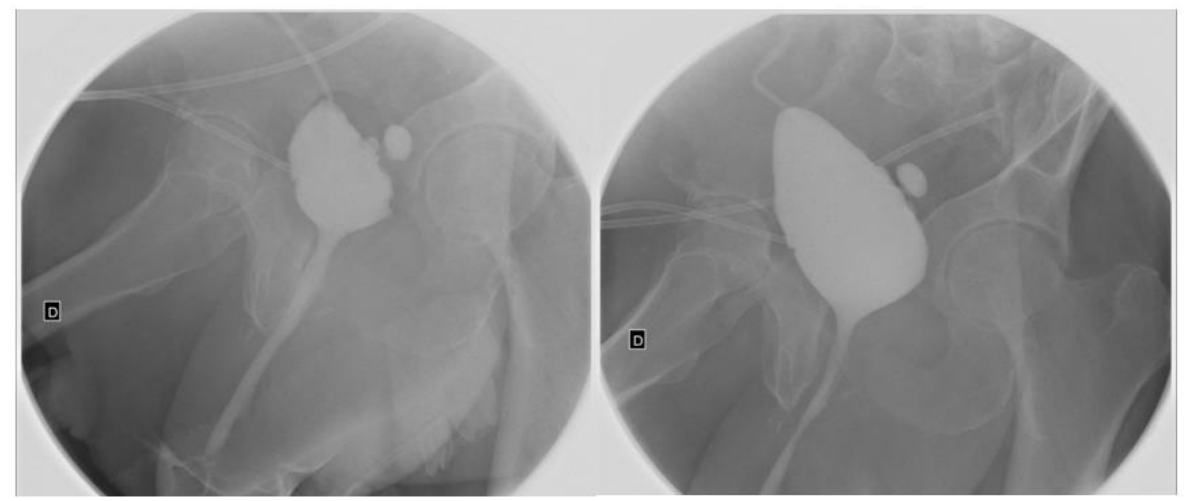

Figure 12: Urethrogram showing a small-capacity multidiverticular bladder and a good-caliber urethra without contrast leakage.

The patient received three cycles of adjuvant treatment with immunotherapy (Cemiplimab $350 \mathrm{mg}$ every 21 days), because was not subsidiary to treatment with platinum for renal failure. At 7 months postoperatively, he was diagnosed with pulmonary metastases associating massive pleural effusion that required thoracentesis in addition to pelvic and local lymph node disease. He died 9 months after the intervention.

\section{Discussion}

We present the case of a 67 -year-old patient diagnosed with perineal squamous cell carcinoma undergoing surgical treatment and subsequent adjuvant immunotherapy with recurrence of the disease 7 months after treatment. The uniqueness of this case is supported by the lack of published case reports describing men patients with this malignancy treated surgically. The two cases previously described were treated (Figure 13), one of them with chemo-radiotherapy and the other with palliative treatment given the advanced state of the disease [1, 4]. From the published literature regarding squamous cell CUP in the pelvic region, the patients described were all women [1].

Carcinomas of unknown primary origin represent $3-5 \%$ of all malignancies and are defined as a heterogeneous group of tumors for which the primary origin cannot be established at the time of diagnosis. Within them, squamous carcinoma of unknown primary origin represents between $5-10 \%$ and are more frequent in the head and neck region, although they are also described at the uterine level and in iliac lymph nodes [1]. The presence of this type of tumors in the pelvic cavity is very rare and the majority of cases described have occurred in women, there are only two cases reported in the literature of perineal carcinoma of unknown origin in men $[1,4]$.

Regarding the pathophysiology of these tumors, several articles have been written relating the inflammatory status with an increase in IL-1 $\beta$ that stimulates the NF- $\mathrm{KB}$ pathway, highly involved in angiogenic and pro-tumorigenic processes [5]. Patients with chronic infections of the 
perineal region, suppurative hidradenitis, urethral fistula, or any inflammatory/infectious process with a torpid evolution at this level should make us rule out the existence of an epidermoid carcinoma [6]. Given the form of presentation and the aggressiveness of this type of tumor, systematic biopsy should be considered in a patient with recurrent

\begin{tabular}{|c|c|c|c|c|c|}
\hline Literature & Age & Presentation & $\begin{array}{l}\text { Metastasis in } \\
\text { other organs }\end{array}$ & Treatment & $\begin{array}{l}\text { Follow up } \\
\text { (months) }\end{array}$ \\
\hline $\begin{array}{l}\text { Chiec et al. } \\
\quad 2014\end{array}$ & 52 & Buttock pain & Liver, Lung & $\begin{array}{l}\text { Chemoradiation (Cisplatin; } \\
6000 \text { centigray in } 30 \\
\text { fractions) }\end{array}$ & 12 \\
\hline $\begin{array}{l}\text { Creta et al. } \\
\quad 2017\end{array}$ & 78 & $\begin{array}{l}\text { Urethral stricture } \\
\text { and perineal } \\
\text { abscess }\end{array}$ & - & Palliative colostomy & 3 \\
\hline Present & 67 & $\begin{array}{l}\text { Urethral stricture } \\
\text { and perineal } \\
\text { abscess }\end{array}$ & $\begin{array}{l}\text { Lung, lymph } \\
\text { nodes }\end{array}$ & $\begin{array}{l}\text { Surgery + immunotherapy } \\
\text { (Cemiplimab } 350 \mathrm{mg} \text { ) }\end{array}$ & 9 \\
\hline
\end{tabular}

Figure 13: Literature review. urethral abscesses, as well as an early MRI to rule out the existence of an underlying tumor. Transperineal biopsy proved to be a valid option for histological diagnosis. In experienced hands, the transperineal route allows access to the small pelvis in complex situations [4].
Based on the limited literature data, it appears that squamous CUP outside of the head and neck region have a more favourable prognosis compared to other CUP and that these malignancies may respond well to a combination of surgical resection, when feasible, local radiotherapy, and platinum-based systemic chemotherapy [1]. Treatment regimens remain controversial, with limited cases to allow for consensus. Surgical intervention remains the leading form of therapy; however, approaches are case-specific, depending on the location of the tumor and the degree of invasiveness [3].

Despite being outside the usual practice, urethral reconstruction with oral mucosa graft may be a good option as long as the tumor does not affect the prostate. It is convenient to give vascular and mechanical support to the neourethra using a muscle flap such as the gracilis. Given the lymphatic drainage territory of the perineal skin and the aggressiveness of the tumor, the systematic performance of inguinal lymph node dissection to control the disease could be considered in the absence of studies that provide solid evidence in this regard. In general, CUP has a poor prognosis, with a median survival time of less than six months [1].

\section{Conclusion}

Squamous cell CUP located in the male pelvis represents a rare entity, so the ideal diagnostic work-up, the optimal treatment strategies, and prognosis are not well determined. Radical surgical treatment followed by adjuvant chemotherapy in patients with a localized tumor and with good baseline status, appears to be the best treatment regimen, especially for local control of symptoms.

\section{Consent}

A written informed consent was given by the patient.

\section{Ethical Approval}

The study was approved by the local Ethics Committee of the Institution.

\section{Conflicts of Interest}

None.

\section{REFERENCES}

1. Chiec L, Verma S, Kendler A, Karim NA (2014) Male pelvic squamous Cell carcinoma of unknown primary origin. Case Rep Oncol Med 2014: 953698. [Crossref]

2. Neagu M, Constantin C, Caruntu C, Dimitru C, Surcel M et al. (2019) Inflammation: A key process in skin tumorigenesis. Oncol Lett 17 4068-4084. [Crossref]

3. Moore SJ, Rashidipour O, Moore RB (2016) Primary Metastatic Squamous Cell Carcinoma of the Male Urethra Presenting with Scrotal Abscess and Subsequent Development of Fournier's Gangrene. Clin Med Insights Case Rep 9: 83-86. [Crossref]

4. Creta M, Mirone V, Di Meo S, Buonopane R, Longo N et al. (2017) A rare case of male pelvic squamous cell carcinoma of unknown primary origin presenting as perineal abscess and urethral stenosis. Arch Ital Urol Androl 89: 154-155. [Crossref]

5. Paulitschke V, Gerner C, Hofstätter E, Mohr T, Mayer RL et al. (2015) Proteome profiling of keratinocytes transforming to malignancy. Electrophoresis 36: 564-576. [Crossref]

6. Kohorst JJ, Shah KK, Hallemeier CL, Baum CL, Davis MDP (2019) Squamous cell carcinoma in perineal, perianal, and gluteal hidradenitis suppurativa: Experience in 12 Patients. Dermatol Surg 45: 519-526. [Crossref] 